\title{
Older adults' attitudes and barriers toward the use of mobile phones
}

This article was published in the following Dove Press journal:

Clinical Interventions in Aging

30 September 2016

Number of times this article has been viewed

\section{Nasrin Navabi \\ Fatemeh Ghaffari \\ Zahra Jannat-Alipoor}

Nursing and Midwifery Department, Babol University of Medical Sciences, Mazandaran, Iran
Correspondence: Fatemeh Ghaffari Nursing and Midwifery Department, Babol University of Medical Sciences, Babol, Mazandaran 469|7I4I4I, Iran Tel +98 II 55225 I5I

Email ghafarifateme@yahoo.com
Background and objectives: The limitations caused by the process of aging and the prevalence of chronic diseases contribute to reduced performance in physical, psychological, and social areas of life in older people. The use of mobile phones as easily accessible portable tools with a high performance is associated with an increased health literacy, self-care, and independence in older people. The present study was conducted to determine older people's attitudes toward the use of mobile phones and the barriers to their use.

Materials and methods: The present descriptive study was conducted on a sample population of 328 individuals older than 60 years presenting to health centers across cities in west Mazandaran, Iran. The data collection tools used included a mobile phone use checklist, a questionnaire on older people's attitude toward the use of mobile phones, and a questionnaire on the barriers to the use of mobile phones. The reliability and validity of these questionnaires were confirmed by the researchers. The data obtained were recorded and then analyzed using SPSS. The level of statistical significance was set at $P \leq 0.05$.

Results: According to the results, $80 \%$ of the older people had regular mobile phones and $20 \%$ had smartphones. In $95 \%$ of the male and $80 \%$ of the female participants, the greatest use of mobile phones pertained to making phone calls. A total of $5 \%$ of the male and $2 \%$ of the female participants used the Internet in their mobile phones. A total of $44 \%$ of the female and $42.80 \%$ of the male participants had poor attitudes (score from 0 to 40 ) toward mobile phone use. As for the different dimensions of the attitude toward mobile phone use, the highest score obtained by the female participants $(71.66 \%)$ pertained to the psychoemotional dimension and the highest score in the male participants $(72.85 \%)$ to the instrumental dimension. The results also revealed the lack of knowledge of English as the greatest barrier to mobile phone use in both sexes. There was a significant relationship between sex and the attitude toward mobile phone use in all the three dimensions examined, the sociocultural, psychoemotional, and instrumental.

Discussion and conclusion: The results of the study revealed that the majority of older people have negative attitudes toward the use of mobile phones as a teaching aid, although they used them for performing daily tasks. Promoting this age group's knowledge about the different mobile phone applications available to help them and increasing their ability to learn the use of these applications through the mass media, family members, and peer groups can help improve older people's attitudes toward the use of mobile phones and thus increase their use of these devices.

Keywords: attitude, mobile phone, barriers to use, older people

\section{Introduction}

Old age is predicted to be the main anthropological phenomenon of the late $21 \mathrm{st}$ century, ${ }^{1}$ as the world's population is aging and the number of older people is expected to reach 2 billion by $2050 .^{2}$ According to the 2011 statistics, older people make up $8.20 \%$ of Iran's population and elderly people make up $67 \%$ of the Mazandaran 
province's population $(3,338,921){ }^{3}$ This growing population needs to be trained to protect and promote its independence and enhance its self-care skills and self-efficacy. Training older people in a variety of topics including nutrition, social activities, and sports can improve their health status and prevent old age disabilities. Due to the numerous problems faced by older people, training can play a major role in enhancing their well-being and quality of life. ${ }^{4}$ In the third millennium, traditional training is replaced by e-learning. ${ }^{5}$ Self-education is an integral part of e-learning. ${ }^{6}$ Mobile phones provide an e-learning tool that is accessible at any time and any place and can serve as a teaching aid to everyone, especially to older people. ${ }^{78}$ In older people, the use of these devices entails advantages such as increased social interaction, diminished feelings of loneliness, ${ }^{6}$ and entertainment. ${ }^{9}$ Some of the problems commonly faced by older people include dementia, social isolation, reduced performance, and weakness in performing daily activities. For example, older people with Alzheimer's disease can refresh their memory by looking at pictures of events from the last 5 minutes on their mobile phone. ${ }^{10}$ Studies show that using mobile phones can enhance older people's ability in different physical, mental, and social dimensions of life through increasing their knowledge, facilitating their communication with friends, receiving emotional support, and enabling their participation in social networks. ${ }^{11}$

Training older patients on the use of different applications is associated with improved effectiveness, coordination, and time management. ${ }^{12}$ These applications can also teach different things such as the proper use of drugs and their side effects, setting the next doctor's appointment, documenting health needs and measures, and enabling membership in social networks of peers. ${ }^{4}$ Studies suggest that older people with chronic diseases who also suffer from the particular physiological problems associated with aging such as reduced mobility can increase their quality of life through using the Internet for communication. ${ }^{13}$ Nevertheless, there are barriers to older people's use of mobile phones, including technological, sociocultural, and economic barriers. ${ }^{14}$ For instance, due to learning problems or poor learning memory, handling the variety of mobile applications available on advanced mobile phones is a major concern for older people using mobile phones. ${ }^{15,16}$ Due to the growing population of older people, efforts directed at promoting their health should be further prioritized by authorities; ${ }^{16,17}$ so the current study is done to find the answer for "how is elderlies attitude toward using mobile phones and the main functional barriers of using them?".

\section{Materials and methods}

This was a cross-sectional study.

\section{Sample}

This study was conducted on a sample population of all the individuals older than 60-70 years presenting to health centers across cities in west Mazandaran, Iran, including Chalous, Noshahr, Tonekabon, and Ramsar. Each of the counted cities has one governmental hospital and three to four health centers, to which the researchers have visited individually and selected their samples according to the convenience sampling method. Every sample took 30-40 minutes for filling the questionnaires. The study inclusion criteria consisted of not suffering from visual or auditory impairment, having a mobile phone, dementia, and psychotic disorders according to his or her medical records. The sample size was calculated as 328 based on a study conducted by Dutton and Blank in $2011^{18}$ and using the sample size formula with a confidence coefficient of $95 \%$ and $d=0.05$. Ethical permission was obtained from the ethics committee of Babol University of Medical Sciences, and the selected older people submitted their written informed consent forms once they were briefed on the study objectives. Among the limitations, it is necessary to mention the low number of samples between 66 and 70 who have got a mobile phone. Data were then collected using the following tools:

\section{Data collection}

1. A demographic questionnaire: type of mobile phone (regular or smartphone), age, sex, level of education, occupation, etc.

2. Mobile phone use checklist: this checklist has been edited according to the following two parts:

- Accessible mobile phone applications for elderlies in Iran.

- Functional mobile phone applications.

The way of answering the questions has been yes or no.

3. A questionnaire on older people's attitude toward the use of mobile phones: To design this instrument, the researcher performed a review of literature and conducted ten individual interviews with older people. The interviews were held using semistructured questions such as "What is your attitude toward the use of mobile phones as a teaching aid?" and "What role do mobile phones have in shaping your social identity?" The first pool of questions included 30 items, 24 of which were 
approved after their face and content validities were examined by ten faculty members with an experience in e-learning. The questionnaire evaluated older people's attitude toward the use of mobile phones in three dimensions, the sociocultural, psychoemotional, and instrumental, and was scored based on a 5-point Likert scale (from strongly agree to strongly disagree). The reliability of the questionnaire was assessed using the test-retest method. The scores obtained ranged from zero to 120 . Obtaining a score of $0-40$ on the questionnaire indicates a negative and unfavorable attitude toward mobile phone use, while obtaining a score of 41-80 indicates a somewhat favorable or average attitude and a score of 81-120 a highly favorable and excellent attitude.

4. A questionnaire on the barriers to the use of mobile phones: to design this instrument, the researcher performed a review of literature and conducted eight individual interviews with older people. Data were collected through semistructured interviews held with questions such as "What do you think are the barriers to mobile phone use among older people?" and "What causes you not to use different applications on your mobile phone?" The first pool of questions included 14 items, eleven of which were approved after their face and content validities were examined by ten faculty members with an experience in e-learning. The reliability of the questionnaire was assessed using the test-retest method $(r=0.89)$. To complete the questionnaire, the researchers asked the older adults to assign priorities to the barriers they perceived to mobile phone use. The items were then classified from 1 to 11 according to the given priorities.

\section{Analysis}

Researchers controlled each form at the step of filling the questionnaire in order to reduce the number of missed questions and being sure about the participant's correct understanding of each question. There were only two useless questionnaires that were omitted, and that is why the number of samples has been reduced to 328 people; hence, sample attrition and the loss of information have got the minimum number.

The data obtained were analyzed using SPSS-18. The mean and the median were calculated, and then Student's $t$-test and chi-squared $\left(\chi^{2}\right)$ test examinations were applied to identify a meaningful relationship between our variables and elderlies' attitudes toward using mobile phones and their barriers. The level of statistical significance was set at $P \leq 0.05$.

\section{Results}

The results obtained showed that $55 \%$ of the female and $62 \%$ of the male participants were retired. A total of $85 \%$ were married, $60 \%$ had below high school education, $80 \%$ had regular mobile phones, and $20 \%$ had smartphones. In $65 \%$ of the cases, the older people's children had motivated them to buy a mobile phone. Only $6 \%$ of the participants browsed the web to find the answer to their health questions and $94 \%$ preferred to find the answer to their questions in person by visiting family members and friends as well as health care providers.

The results also showed the greatest use of mobile phones in both cases (Table 1).

A total of $44 \%$ of the female and $42.80 \%$ of the male participants had unfavorable attitudes toward the use of mobile phones. As for the different dimensions of the attitude toward mobile phone use, the highest score obtained by the female participants $(71.66 \%)$ pertained to the psychoemotional dimension and the highest score in the male participants $(72.85 \%)$ to the instrumental dimension (Table 2).

The results obtained showed a significant relationship between sex and the attitude toward mobile phone use in all the three dimensions, namely the sociocultural, psychoemotional, and instrumental dimensions. The chi-square values obtained in the sociocultural, psychoemotional, and instrumental dimensions were 8.01, 9.9, and 13.85 , in respective order. All the values were larger than the chi-square values in the table with a degree of freedom of 2 (2.92) and a confidence level of 0.95. These findings support the hypothesis that a significant relationship exists between sex and the attitude toward mobile phone use in older people (Table 3).

The results also revealed the lack of knowledge of English as the greatest barrier to mobile phone use in both sexes. The second greatest barrier to mobile phone use was the inability to upgrade the mobile software or make other software changes in the female participants and being costly in the male participants (Table 4).

\section{Discussion}

The results obtained showed that the greatest use of mobile phones in both sexes pertains to making phone calls and sending text messages and the least to using the Internet. In a study by Lelkes, ${ }^{19}$ the main reasons for older people's failure to use the Internet on their mobile phones included low levels of literacy, disrupted mobility, delayed learning, and forgetfulness. ${ }^{19}$ Studies have reported ten factors to affect 
Table I The percentage of mobile phone usage in the elderly

\begin{tabular}{|c|c|c|c|c|c|c|c|c|}
\hline \multirow[t]{3}{*}{ Question } & \multicolumn{4}{|l|}{ Men } & \multicolumn{4}{|l|}{ Women } \\
\hline & \multicolumn{2}{|l|}{ Yes } & \multicolumn{2}{|l|}{ No } & \multicolumn{2}{|l|}{ Yes } & \multicolumn{2}{|l|}{ No } \\
\hline & $\begin{array}{l}\text { Absolute } \\
\text { frequency }\end{array}$ & Percent & $\begin{array}{l}\text { Absolute } \\
\text { frequency }\end{array}$ & Percent & $\begin{array}{l}\text { Absolute } \\
\text { frequency }\end{array}$ & Percent & $\begin{array}{l}\text { Absolute } \\
\text { frequency }\end{array}$ & Percent \\
\hline Calling others & 131 & 80 & 32 & 20 & 155 & 95 & 8 & 5 \\
\hline Sending text messages & 82 & 50 & 82 & 50 & 123 & 75 & 24 & 15 \\
\hline Using social networks such as Viber & 13 & 8 & 151 & 92 & 16 & 10 & 148 & 90 \\
\hline Using the radio of mobile phones & 7 & 4 & 157 & 96 & - & - & 164 & 100 \\
\hline Using mobile phones to record voices & 17 & 10 & 147 & 90 & 20 & 12 & 144 & 88 \\
\hline Recording voices and images & 10 & 6 & 154 & 94 & 13 & 8 & $|5|$ & 92 \\
\hline Taking photos & 33 & 20 & $13 \mid$ & 80 & 20 & 12 & 144 & 88 \\
\hline Using the note of mobile phones & 4 & 2 & 160 & 98 & 0 & - & 164 & 100 \\
\hline $\begin{array}{l}\text { Using the alarm to alert a specific time } \\
\text { such as drug use }\end{array}$ & 33 & 20 & $13 \mid$ & 80 & 8 & 5 & 156 & 95 \\
\hline Using training software in mobile phones & 5 & 3 & 159 & 97 & - & - & 164 & 100 \\
\hline $\begin{array}{l}\text { Using the applications of mobile phones } \\
\text { such as calculators and convertors }\end{array}$ & 20 & 12 & 144 & 88 & - & - & 164 & 100 \\
\hline Using the clock of mobile phones & 2 & I & 162 & 99 & - & - & 164 & 100 \\
\hline Using the calendar of mobile phones & - & - & 164 & 100 & - & - & 164 & 100 \\
\hline Using the navigation of mobile phones & - & - & 164 & 100 & - & - & 164 & 100 \\
\hline Using the Internet & 8 & 5 & 156 & 95 & 3 & 2 & 161 & 98 \\
\hline Using for bank tasks & 18 & II & 146 & 89 & 3 & 2 & 161 & 98 \\
\hline Using the mobile phone games & - & - & 164 & 100 & - & - & 164 & 100 \\
\hline
\end{tabular}

Note: “-” Indicates data not available.

the use of technology by older people, including awareness about the value of technology use, the price of the devices, accessibility, technical support, social support, feelings, individual independence, experience, and self-confidence. In general, older people with psychological problems and a poor independence do not have good prospects for using technologies and buying devices. ${ }^{20,21}$ In a study by Gatto and Tak, ${ }^{22} 47 \%$ of individuals aged $>65$ years were found to benefit from online shopping and banking. In a study by Hill et al, ${ }^{23} 6 \%$ of older people visited Internet cafes to access the web.

The results of the present study showed that the majority of the participants had unfavorable attitudes toward mobile phone use. Other studies show that older people have a generally negative attitude toward the use of mobile phones due to technology anxiety and the fear of working with new devices. For example, aging tends to make the selection of a specific button on the mobile phone difficult or make the use of mobile applications confusing and thus creates anxiety in the older adult. Fear of cyber victimization, reduced face-toface interactions, and receiving spam email are some of the other factors contributing to the negative attitudes toward mobile phone use among older people. ${ }^{24,25}$ In a study conducted by Feist et al, ${ }^{26}$ individuals aged $>79$ years reported that learning to work with a new technology was difficult for them. This problem was also observed in $22 \%$ of the 65 - to 69-year-old individuals examined. Older people's interest in using new technologies appears to have diminished. Dutton and Blank ${ }^{27}$ reported poor attitudes in older people toward using the web due to reasons such as previous experiences with mobile viruses and data loss and the inability to cope with these difficulties. Positive attitudes toward mobile phone use can be instilled in older people through encouraging them to use and adapt to advanced technologies ${ }^{28}$ raising their awareness about the availability of mobile phones and their potential for improving communication with sources of emergency help and routine assistance, security, and psychological ease. ${ }^{29}$

The attitude scores obtained in the present study were lower in females than in males, which is consistent with the findings of a study conducted in 2015 by Masoudnia; ${ }^{30}$ however, no differences were observed between the sexes in terms of learning to use mobile phones and their application. ${ }^{31}$

The results also showed that the lack of knowledge of English is the greatest barrier to mobile phone use in both sexes. The elderlies who were among our study mostly did not have an academic degree and that is why they counted English language as a barrier of using their mobile phones since even installing a simple application needs a little knowledge of English for following correct steps. Peek ${ }^{24}$ reported a group of factors such as technological knowledge as effective 


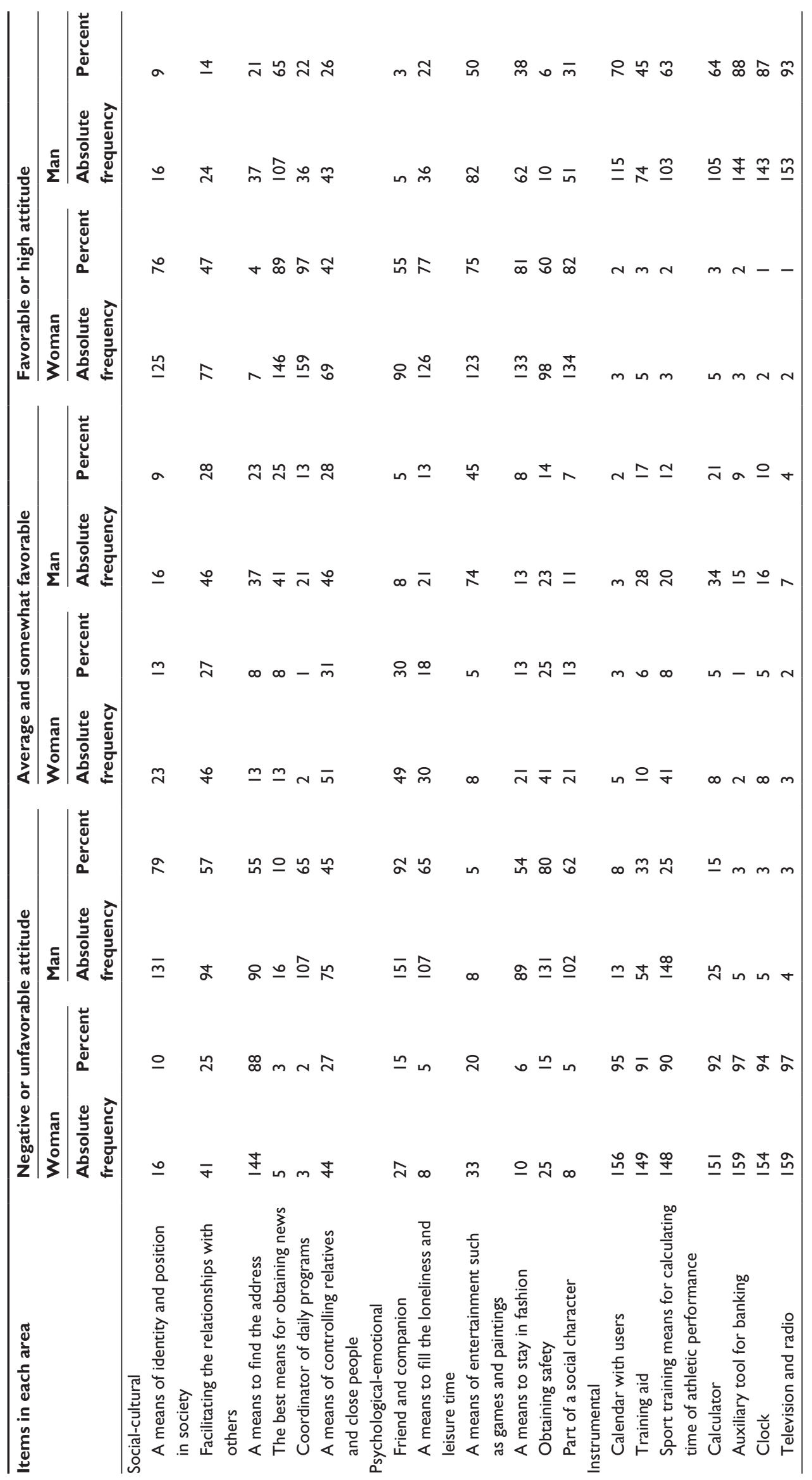


Table 3 The relationship between sex and the dimensions of the attitude toward mobile phone use in the statistical population

\begin{tabular}{|c|c|c|c|c|}
\hline $\begin{array}{l}\text { Attitude } \\
\text { classification }\end{array}$ & $\begin{array}{l}\text { Unfavorable } \\
\text { or negative }\end{array}$ & $\begin{array}{l}\text { Average and } \\
\text { somewhat favorable }\end{array}$ & Favorable & $\begin{array}{l}\text { Level of } \\
\text { significance }\end{array}$ \\
\hline Attitude dimension & SD \pm mean & Mean \pm SD & Mean \pm SD & \\
\hline \multicolumn{5}{|l|}{ Psychoemotional } \\
\hline Female & $136 \pm 0.17$ & $0.91 \pm 0.11$ & $3.2 \pm 0.4$ & $P \leq 0.05$ \\
\hline Male & $0.46 \pm 3.04$ & $0.27 \pm 1.21$ & $0.18 \pm 1.46$ & $X=9.9$ \\
\hline \multicolumn{5}{|l|}{ Sociocultural } \\
\hline Female & $0.80 \pm 0.64$ & $0.20 \pm 1.006$ & $0.61 \pm 4.21$ & $P \leq 0.05$ \\
\hline Male & $0.58 \pm 3.48$ & $0.05 \pm 0.46$ & $0.2 \pm 1.4$ & $X=8 / 0 I$ \\
\hline \multicolumn{5}{|l|}{ Instrumental } \\
\hline Female & $0.9 \pm 6.29$ & $0.02 \pm 0.2$ & $0.03 \pm 0.14$ & $P \leq 0.05$ \\
\hline Male & $0.12 \pm 0.9$ & $0.13 \pm 0.9$ & $0.6 \pm 5.1$ & $X=13 / 85$ \\
\hline
\end{tabular}

in the use of technology. In other studies, the barriers to mobile phone use in older people included mobility problems such as hand tremors when using a touch screen and delays in deciding on which icons to choose on the screen. ${ }^{32}$ The other barriers included the prolonged search for icons and difficulty identifying them, physical problems, font type and color, low voice quality, quickly forgetting the points learnt, problems in learning, rapid technological changes, and the need to update the software and applications. ${ }^{33}$ Takahashi et $\mathrm{al}^{34}$ reported being untrained in fields of technology as an inhibiting factor of technology use among older people. Since the use of mobile phones and the facilities they provide requires a certain degree of technological knowledge, older people can also be encouraged to use mobile phones through installing applications tailored to their language and through introducing them to mobile phones with larger screens. Mobile phone designers and producers should produce some with large buttons, autoupdating applications, functional self-translating orders, and steps besides putting visual guides in order to let even elderlies have a pleasant experience of using mobile phones.

\section{Conclusion}

The results of the study revealed that the majority of older people have negative attitudes toward the use of mobile phones as a teaching aid, although they used them for performing daily tasks. Promoting this age group's knowledge about the various mobile phone applications available to help them and increasing their ability to use applications through the mass media, family members, and peer groups can help improve older people's attitudes toward the use of mobile phones and thus increase their actual use of these devices.

Table 4 Percentage of mobile usage barriers from older people's perspective

\begin{tabular}{|c|c|c|c|c|c|}
\hline \multirow[t]{2}{*}{ No } & \multirow[t]{2}{*}{ Items } & \multicolumn{2}{|l|}{ Women } & \multicolumn{2}{|l|}{ Men } \\
\hline & & Frequency & Percent & Frequency & Percent \\
\hline 1 & Being costly & 139 & 85 & 159 & 95 \\
\hline 2 & Reducing the possibility of face to face interaction & 115 & 70 & 131 & 80 \\
\hline 3 & Possible hazards such as tumors, headaches, etc. & 66 & 40 & 123 & 75 \\
\hline 4 & Learning delays and reduced learning & 110 & 67 & 115 & 70 \\
\hline 5 & $\begin{array}{l}\text { Mistake in choosing the key or written and tactile commands } \\
\text { for mobile phones (especially on the touch screen) }\end{array}$ & 98 & 60 & 89 & 54 \\
\hline 6 & $\begin{array}{l}\text { Reducing the personal border preservation such as a } \\
\text { person's privacy (openness of mobile windows, losing it, etc.) }\end{array}$ & 107 & 65 & 74 & 45 \\
\hline 7 & Inability in upgrading mobile phones and software changes & 144 & 88 & 57 & 35 \\
\hline 8 & $\begin{array}{l}\text { Being afraid of filling the phone's memory (inability to empty } \\
\text { messages, etc.) }\end{array}$ & 71 & 43 & 49 & 30 \\
\hline 9 & $\begin{array}{l}\text { Sending wrong written instructions because of the speed and } \\
\text { touch of writing in motion }\end{array}$ & 57 & 35 & 34 & 21 \\
\hline 10 & No Internet access & 33 & 20 & 30 & 18 \\
\hline II & Lack of familiarity with English & 161 & 98 & 162 & 99.30 \\
\hline
\end{tabular}




\section{Acknowledgments}

The present study was approved by the ethics committee of Babol University of Medical Sciences under No 3705. The authors would like to express their gratitude to all the older people who helped conduct the study.

\section{Author contributions}

All authors contributed toward data analysis, drafting and critically revising the paper and agree to be accountable for all aspects of the work.

\section{Disclosure}

The authors report no conflicts of interest in this work.

\section{References}

1. Boellstorff T. Coming of age in Second Life: An anthropologist explores the virtually human. Princeton University Press; March 24th 2016. Available at: http://press.princeton.edu/titles/10611.html. Accessed June 21, 2016.

2. Vichitvanichphong S, Talaei-Khoei A, Kerr D, Ghapanchi AH, editors. Adoption of assistive technologies for aged care: a realist review of recent studies. System sciences (HICSS). 2014 47th Hawaii International Conference on System Sciences. Waikoloa, HI: IEEE; 2014: 2706-2715.

3. Seyedrasooli E, Valizadeh L, Nasiri K, Zamanzadeh V, Goljariyan S, Ghasemi O. The effect of reflexology on sleep quality of elderly: a single-blind clinical trial. Med Surg Nurs J. 2013;2(1-2):11-18.

4. Deng Z, Mo X, Liu S. Comparison of the middle-aged and older users' adoption of mobile health services in China. Int J Med Inform. 2014;83(3):210-224.

5. Mohamad M, Maringe F, Woollard J. Mobile learning in Malaysian schools: opportunities and challenges of introducing teaching through mobile phones. Int J e-Learn Secur. 2012;2(1-2):133-137.

6. Plaza I, MartíN L, Martin S, Medrano C. Mobile applications in an aging society: status and trends. J Syst Software. 2011;84(11):1977-1988.

7. Wenze SJ, Armey MF, Miller IW. Feasibility and acceptability of a mobile intervention to improve treatment adherence in bipolar disorder a pilot study. Behav Modif. 2014;38(4):497-515.

8. Hsu L, Lee S-N. Learning tourism English on mobile phones: how does it work? J Hospit Leisure Sports Tourism Educ. 2011;10(2):85.

9. Kwan A [webpage on the Internet]. Mhealth Solutions for Improving Mental Health and Illnesses in the Aging Process. 2013. Available from: http://www.mhealthknowledge.org/sites/default/files/7_mHAAging-Paper3_092713.pdf. Accessed March 24, 2016.

10. De Leo G, Brivio E, Sautter SW. Supporting autobiographical memory in patients with Alzheimer's disease using smart phones. Appl Neuropsychol. 2011;18(1):69-76.

11. Morris ME, Aguilera A. Mobile, social, and wearable computing and the evolution of psychological practice. Prof Psychol Res Pract. 2012; 43(6):622.

12. Banos O, Villalonga C, Garcia R, et al. Design, implementation and validation of a novel open framework for agile development of mobile health applications. Biomed Eng Online. 2015;14(S2):1-20.

13. Ziefle M, Schaar AK. Technology acceptance by patients: empowerment and stigma. Handbook of Smart Homes, Health Care and Well-Being. New York: Springer; 2014:30-100.

14. Schaar AK, Valdez AC, Ziefle M. Social media for the ehealth context A requirement assessment. Adv Hum Aspect Healthcare. 2012:79.
15. Börsch-Supan A, Brandt M, Litwin H, Weber G. Active Ageing and Solidarity between Generations in Europe: First Results from SHARE after the Economic Crisis. Berlin: Walter de Gruyter; 2013.

16. Morris M, Ozanne E, Miller K, et al. Smart Technologies for Older People: A Systematic Literature Review of Smart Technologies that Promote Health and Wellbeing of Older People Living at Home. Melbourne, VIC: IBES, The University of Melbourne; 2012.

17. Vicente P, Lopes I. Attitudes of older mobile phone users towards mobile phones. Communications. 2016;41(1):71-86.

18. Dutton WH, Blank G [webpage on the Internet]. Next Generation Users: The Internet in Britain. 2011. Available from: http://goo.gl/PpI9Pp. Accessed March 24, 2016.

19. Lelkes O. Happier and less isolated: internet use in old age. J Poverty Soc Justice. 2013;21(1):33-46.

20. Sanders C, Rogers A, Bowen R, et al. Exploring barriers to participation and adoption of telehealth and telecare within the whole system demonstrator trial: a qualitative study. BMC Health Serv Res. 2012; 12(1):220.

21. Lee C, Coughlin JF. Perspective: older adults' adoption of technology: an integrated approach to identifying determinants and barriers. J Prod Innov Manage. 2015;32(5):747-759.

22. Gatto SL, Tak SH. Computer, Internet, and e-mail use among older adults: benefits and barriers. Educ Gerontol. 2008;34(9):800-811.

23. Hill R, Beynon-Davies P, Williams MD. Older people and internet engagement: acknowledging social moderators of internet adoption, access and use. Inform Tech People. 2008;21(3):244-266.

24. Peek ST, Wouters EJ, van Hoof J, Luijkx KG, Boeije HR, Vrijhoef HJ. Factors influencing acceptance of technology for aging in place: a systematic review. Int J Med Inform. 2014;83(4):235-248.

25. Samantha J, Parker SJ, Richardson JE, Reid MC. Older adults are mobile too! Identifying the barriers and facilitators to older adults' use of mHealth for pain management. BMC Geriatr. 2013; 13(43):1-8.

26. Feist HPK, Howard N, Hugo G. New technologies: their potential role in linking rural older people to community. Int J Emerg Technol Soc. 2010;8(2):68.

27. Dutton WH, Blank G. Cultures of the Internet: The Internet in Britain. Oxford: The University of Oxford for the Oxford Internet Institute; 2013.

28. Mason M, Sinclair D, Berry C. Nudge or Compel? Can Behavioural Economics Tackle the Digital Exclusion of Older People. The International Longevity Centre UK; 2012. Available from: http://www.ilcuk. org.uk/index.php/publications/publication_details/nudge_or_compel_can_behavioural_economics_tackle_the_digital_exclusion_of_o. Accessed June 23, 2016.

29. Plant $\mathrm{S}$ [webpage on the Internet]. The Effects of Mobile Telephones on Social and Individual Life. Report Commissioned by Motorola. 2000. Available from: http://www.momentarium.org/experiments/7a10me/ sadie_plant.pdf. Accessed March 26, 2016.

30. Masoudnia E. Public perceptions about HIV/AIDS and discriminatory attitudes toward people living with acquired immunodeficiency syndrome in Iran. J Soc Aspect HIV/AIDS. 2015;12(1):116-122.

31. Park YJJS. Understanding privacy knowledge and skill in mobile communication. Comput Human Behav. 2014;38:296-303.

32. Al-Razgan MS, Al-Khalifa HS, Al-Shahrani MD, AlAjmi HH. Touchbased mobile phone interface guidelines and design recommendations for elderly people: a survey of the literature. ICONIP'12 Proceedings of the 19th International Conference on Neural Information Processing. Vol. IV. 2012:568-574.

33. Hardill IOC. Staying connected: exploring mobile phone use amongst older adults in the UK. Geoforum. 2012;43(6):1306-1312.

34. Takahashi PY, Chandra A, North F, Pecina JL, Upatising B, Hanson GJ. Telemedicine: an enhanced emergency care program for older adults. Smart Homecare Technol TeleHealth. 2014;2:55-62. 


\section{Publish your work in this journal}

Clinical Interventions in Aging is an international, peer-reviewed journal focusing on evidence-based reports on the value or lack thereof of treatments intended to prevent or delay the onset of maladaptive correlates of aging in human beings. This journal is indexed on PubMed Central, MedLine,

CAS, Scopus and the Elsevier Bibliographic databases. The manuscript management system is completely online and includes a very quick and fair peer-review system, which is all easy to use. Visit http://www.dovepress. com/testimonials.php to read real quotes from published authors. 